\title{
Pengaruh Pola Tanam Tumpang Sari terhadap Produktivitas Rimpang dan Kadar Senyawa Aktif Temulawak (Curcuma xanthorrhiza Roxb.)
}

Penulis

Afiliasi
Poppy F. Arifin ${ }^{1,{ }^{*}}$,Lucky Lia Faiza ${ }^{1}$, Waras Nurcholis ${ }^{2}$, Taufik Ridwan $^{2}$, Irmanida Batubara ${ }^{2}$, Raphael Aswin Susilowidodo ${ }^{1}$, Rosalina Wisastra ${ }^{1}$

\footnotetext{
${ }^{1}$ SOHO Centre of Excellence in Herbal Research (SCEHR), SOHO Global Health

${ }^{2}$ Pusat Studi Biofarmaka Tropika, Lembaga Penelitian dan Pengabdian Kepada Masyarakat, Institut Pertanian Bogor
}

\section{Kata Kunci \\ $\rightarrow$ Temulawak \\ O Tumpang sari \\ - Budi daya Temulawak \\ $\rightarrow$ Pola tanam}

*Penulis korespondensi Poppy F. Arifin

SOHO Centre of Excellence in Herbal Research (SCEHR), Cihanjawar, Nagrak, Sukabumi 43356, Indonesia Email :

poppy.arifin@sohoglobalhealt h.com

\section{ABSTRAK}

Temulawak (Curcuma xanthorrhiza Roxb. Synm. Curcuma javanica) merupakan tanaman obat asli Indonesia yang memiliki khasiat multifungsi. Namun jangka waktu panen temulawak yang cukup lama (sekitar 9-12 bulan) menyebabkan para petani enggan menanam tanaman temulawak. Untuk itu pengembangan metode penanaman perlu dilakukan agar menguntungkan secara ekonomis bagi petani, salah satu metode yang dapat digunakan adalah tumpang sari.

Tumpang sari adalah penanaman lebih dari satu tanaman pada waktu yang bersamaan atau selama periode tanam pada satu tempat yang sama. Beberapa keuntungan dari metode tumpang sari antara lain pemanfaatan lahan kosong diselasela tanaman pokok, penggunaan cahaya, air serta unsur hara yang lebih efektif, mengurangi resiko kegagalan panen, dan menekan pertumbuhan gulma.

Penelitian temulawak dilakukan dengan menggunakan rancangan petak-petak terbagi (split plot design). Rancangan acak kelompok (RAK) dibagi menjadi 3 kelompok berdasarkan variabel jarak tanam, jumlah tunas, dan waktu panen. Parameter agronomi yang diamati adalah bobot rimpang basah dan kering yang mengindikasikan produktivitas per tanaman dan jumlah per bagian rimpang. Kandungan bioaktif xanthorrhizol dan kurkuminoid pada temulawak ditentukan dengan metode Kromatografi Cair Kinerja Tinggi (KCKT).

Hasil pengukuran kurkuminoid dan xanthorrhizol pada temulawak menunjukkan bahwa tidak ada perbedaan yang signifikan pada kadar kedua metabolit sekunder dari penanaman dengan dan tanpa tumpang sari. Dapat disimpulkan bahwa metode penanaman tumpang sari dapat tidak mempengaruhi kadar metabolit sekunder dari temulawak sebagai tanaman utama, sehingga dapat menjadi pilihan metode pertanian untuk meningkatkan manfaat ekonomi para petani temulawak.

\section{PENDAHULUAN}

Temulawak (Curcuma xanthorriza Roxb.) merupakan salah satu tumbuhan obat suku Zingiberaceae yang banyak tumbuh dan dipakai sebagai obat tradisional di 
Indonesia. Temulawak diketahui memiliki banyak manfaat antara lain sebagai antiinflamasi (Jacob 2007), antioksidan (Kumar et al. 2007), antikanker (Thangapazham et al. 2008), antimikroba (Goel 2008), hepatoprotektif (Farombi et al. 2007), dan antihiperlipidemia (Arafa 2005). Senyawa metabolit sekunder dalam temulawak yang banyak dimanfaatkan antara lain adalah pati, kurkuminoid, dan minyak atsiri (Sidik dan Sumiwi 2008).

Faktor-faktor yang mempengaruhi produksi metabolit sekunder diantaranya adalah variasi fisiologis meliputi perkembangan organ, aktivitas penyerbukan, dan terjadinya cidera baik kimia maupun mekanis. Selain itu, kondisi lingkungan yang juga mempengaruhi terbentuknya metabolit sekunder adalah musim, iklim, cemaran, hama dan penyakit, serta edaphic factor (kondisi tanah) (Figueiredo et al. 2008).

Namun dengan segala manfaat kesehatan dari temulawak ternyata tingkat hasil panen temulawak masih tergolong rendah, sehingga menyebabkan pasokan untuk kebutuhan obat tradisional dan industri fitofarmasi di Indonesia menjadi kurang maksimal. Beberapa faktor yang pada umumnya menjadi penyebab rendahnya hasil panen temulawak, antara lain tidak tersedianya varietas unggul, kurangnya standardisasi benih berkualitas, teknik budi daya yang belum berjalan baik dan keengganan petani untuk menanam temulawak (Rahardjo 2010). Banyak penelitian terkait penyediaan varietas unggul, standardisasi benih dan optimasi teknik budi daya yang telah dilakukan untuk meningkatkan hasil panen temulawak, namun belum banyak penelitian yang dilakukan terkait keengganan petani untuk menanam temulawak sebagai tanaman utama karena jangka waktu panen temulawak yang cukup lama yakni sekitar 9-12 bulan (Devy 2009). Oleh karena itu, pengaruh penerapan metode budi daya tumpang sari temulawak terhadap produktivitas rimpang dan kadar bahan aktif temulawak menjadi menarik untuk diteliti.

Tumpang sari adalah penanaman lebih dari satu tanaman pada waktu yang bersamaan atau selama periode tanam pada satu tempat yang sama. Beberapa keuntungan dari metode tumpang sari antara lain pemanfaatan lahan kosong disela-sela tanaman pokok, penggunaan cahaya, air serta unsur hara yang lebih efektif, mengurangi resiko kegagalan panen, dan menekan pertumbuhan gulma (Herlina 2011).

Dalam pola tanam tumpang sari terdapat prinsip yang harus diperhatikan, yaitu: tanaman yang ditanam secara tumpang sari sebaiknya mempunyai umur atau periode pertumbuhan yang tidak sama, mempunyai perbedaan kebutuhan terhadap faktor lingkungan seperti air, kelembapan, cahaya dan unsur hara tanaman, yang keseluruhan hal tersebut akan berpengaruh terhadap alelopati (Indriati 2009). Penanaman secara tumpang sari mempunyai empat aspek pengelolaan, yaitu pengelolaan jarak tanam dan pola tanam, pengelolaan populasi tanaman, pengelolaan waktu yang tepat, dan pengelolaan pemupukan (Islam et al. 2002).

Tanaman jagung merupakan salah satu pilihan tanaman yang dapat digunakan pada metode tumpang sari temulawak ini. Hal tersebut disebabkan oleh usia panen tanaman jagung yang cukup pendek yakni sekitar 3-4 bulan. sehingga dapat menambah nilai ekonomis bagi petani temulawak. Penerapan metode tumpang sari dapat mempengaruhi kondisi tanah dengan memberikan efek yang signifikan pada kondisi mikrobiota dan sifat kimia di rhizosfer. Meskipun demikian, pengaruh tumpang sari terhadap kandungan metabolit sekunder temulawak masih belum diketahui dan menarik untuk diteliti lebih lanjut.

Jarak pola tanam monokultur dengan tumpang sari tentunya memiliki perbedaan. Namun detail informasi aplikatif teknik budi daya tersebut masih belum ada, khususnya pada pola tanam tumpang sari sehingga informasi masih perlu dikaji lebih lanjut. Oleh karena itu, penelitian terkait tumpang sari ini bertujuan untuk mengkaji pengaruh metode penanaman terhadap produktivitas rimpang temulawak dan kadar metabolit sekunder yang terkandung, sehingga metode tersebut dapat dijadikan pilihan metode pertanian yang dapat meningkatkan manfaat ekonomi para petani temulawak.

\section{METODE}

Alat-alat yang digunakan dalam penelitian ini meliputi alat untuk proses penanaman dan pengolahan simplisia yaitu cangkul, garpu, clurit, skop, alat pencuci, mesin perajang, dan moisture analyzer. Sedangkan untuk proses analisa hasil diperlukan alat-alat gelas (Beaker gelas, tabung centrifuge, pipet tetes, erlenmeyer, labu takar), blender, timbangan, centrifuge, ultrasonik, dan Kromatografi Cair Kinerja Tinggi (KCKT). Bahan-bahan yang digunakan adalah benih temulawak varietas Cursina 2, benih jagung Pioneer, pupuk kandang, rimpang temulawak, etanol, 
standar kurkuminoid dan xanthorrhizol, asetonitril, $\mathrm{H}_{3} \mathrm{PO}_{4}$, akuades, dan bahan-bahan analisis lainnya.

\section{Metode Kultivasi}

Penelitian ini dilakukan pada Januari-September 2016 di SOHO Centre of Excellence in Herbal Research (SCEHR) yang berlokasi di Desa Cihanjawar, Nagrak, Sukabumi, Jawa Barat dengan ketinggian 100-600 m di atas permukaan laut. Lahan memiliki sistem pengairan yang baik dan pemupukan dilakukan dengan menggunakan pupuk kandang $1 \mathrm{~kg} / \mathrm{lubang}$.

Penelitian dilakukan dengan menggunakan rancangan petak terbagi (split plot design). Jarak tanam yang dapat digunakan untuk tumpangsari tanaman temulawak adalah $75 \mathrm{~cm} \times 60 \mathrm{~cm}$ dan $75 \mathrm{~cm} \times 50 \mathrm{~cm}$, sementara untuk pola monokultur dengan jarak tanam $50 \mathrm{~cm} \times 50 \mathrm{~cm}$ (Rahardjo 2010). Rancangan acak kelompok (RAK) dibagi menjadi 3 kelompok berdasarkan variabel jarak tanam, jumlah tunas, dan waktu panen.

Sebagai petak utama (main plot) adalah jarak tanam temulawak yang terdiri dari 3 taraf, yaitu temulawak 50 $\mathrm{cm} \times 50 \mathrm{~cm}$ tanpa jagung; temulawak $75 \mathrm{~cm} \times 60 \mathrm{~cm}$ dan jagung $100 \mathrm{~cm} \times 60 \mathrm{~cm}$; dan temulawak $75 \mathrm{~cm} \times 50$ $\mathrm{cm}$ dan jagung $100 \mathrm{~cm} \times 60 \mathrm{~cm}$. Sebagai anak petak (sub plot) adalah jumlah tunas bibit temulawak, meliputi 2 taraf: 1-2 tunas; dan $\geq 3$ tunas. Sedangkan untuk sub-anak petak adalah waktu panen, terdiri 3 taraf: 5 bulan setelah tanam ; 7 bulan setelah tanam; 9 bulan setelah tanam. Pada panen, parameter agronomi yang diamati adalah bobot rimpang basah dan kering untuk menggambarkan produktivitas per tanaman dan jumlah per bagian rimpang. Kandungan bioaktif xanthorrhizol dan kurkuminoid pada simplisia tanaman temulawak dianalisa dengan metode KCKT.

\section{Metode Analisa Temulawak Preparasi bahan baku}

Preparasi bahan baku dilakukan dengan penanganan rimpang temulawak yang sudah dipanen melalui beberapa tahap yaitu pencucian dan penyortiran, perajangan, dan pengeringan. Tujuan pencucian dan penyortiran basah yaitu memisahkan rimpang dari kotoran berupa tanah, sisa tanaman, dan gulma. Pencucian dilakukan dengan air bersih, setelah pencucian selesai, sampel ditiriskan dan ditempatkan dalam wadah yang bersih, kemudian dilakukan penimbangan bobot basah temulawak.
Rimpang yang sudah bersih dirajang melintang dengan menggunakan mesin perajang sehingga menghasilkan ketebalan tertentu. Hasil rajangan kemudian dikeringkan di bawah sinar matahari sampai kadar air $<10 \%$. Pengukuran kadar air ditentukan dengan alat moisture analyzer.

\section{Penentuan kadar kurkuminoid}

Kadar kurkuminoid simplisia ditentukan dengan metode KCKT. Kolom yang digunakan adalah $\mathrm{C} 18$, 250x4.6 mm, $5 \mu \mathrm{m}$ dengan fase gerak asetronitril: $\mathrm{H}_{3} \mathrm{PO}_{4}$ $0.1 \%$ (60:40) dan dideteksi pada panjang gelombang $425 \mathrm{~nm}$. Senyawa uji muncul pada waktu retensi \pm 7.2 menit untuk Bis-demetoksikurkumin, waktu retensi \pm 7.8 menit untuk demetoksikurkumin dan waktu retensi \pm 8.4 menit untuk kurkumin.

\section{Penentuan kadar xanthorrhizol}

Penentuan kadar xanthorrhizol dilakukan dengan menginjeksikan sampel yang telah dilarutkan dalam etanol ke sistem KCKT. Kolom yang digunakan adalah C18, 150x4. $6 \mathrm{~mm}, 5 \mu \mathrm{m}$ dengan fase gerak metanol:air (80:20) dan dideteksi pada panjang gelombang $280 \mathrm{~nm}$. Senyawa uji muncul pada waktu retensi \pm 9.6 menit.

\section{HASIL DAN PEMBAHASAN}

Produksi rimpang merupakan komponen hasil utama dalam sebuah sistem budi daya tanaman temulawak. Rimpang temulawak meliputi rimpang induk, anak, dan cucu. Secara terminologi bagian rimpang dibagi menjadi rimpang primer dan sekunder untuk induk dan anak secara berurutan, sedangkan yang dimaksud rimpang cucu merupakan ujung akar yang membesar yang dimungkinkan berfungsi sebagai penyimpanan makanan, dapat dilihat pada Gambar 1 .

Tabel 1 menunjukkan produktivitas rimpang basah dan kering tanaman temulawak tumpang sari dengan jagung. Rata-rata produksi rimpang induk basah adalah 160.00-346.67 g sedangkan rimpang induk kering adalah 18.00-48.13 g per rumpun. Produksi rimpang anak basah sekitar 179.67-340.00 g per rumpun dan yang kering sekitar 13.13-37.73 g per rumpun. Sementara itu pada rimpang cucu basah menunjukkan bahwa produktivitas mencapai 105.67-340.00 g per rumpun sedangkan yang kering mencapai 3.67-22.13 g per rumpun. 


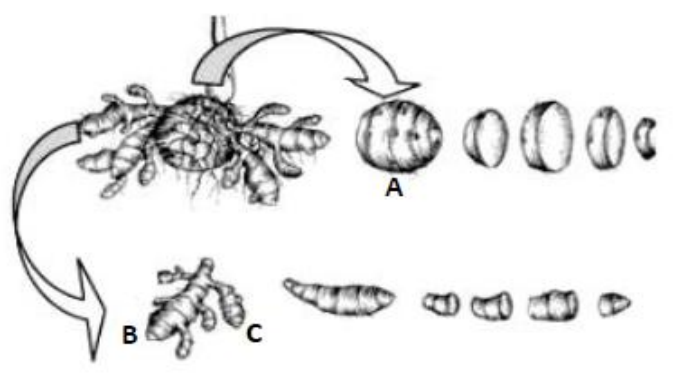

Gambar 1 Percabangan rimpang temulawak. A) Induk; B) Anak; C) Cucu

Tabel 1 Pengaruh jarak tanam, tunas bibit dan umur panen tanaman temulawak tumpang sari jagung terhadap produktivitas rimpang per rumpun tanaman temulawak

\begin{tabular}{|c|c|c|c|c|c|c|c|c|c|}
\hline \multirow{2}{*}{\multicolumn{2}{|c|}{ Perlakuan }} & \multirow{2}{*}{\multicolumn{4}{|c|}{$\begin{array}{c}\text { Produktivitas Rimpang (g / rumpun) } \\
\text { Umur Tanaman Panen (bst) }\end{array}$}} & \multirow{2}{*}{\multicolumn{4}{|c|}{$\begin{array}{c}\text { Produktivitas Rimpang (g/rumpun) } \\
\text { Umur Tanaman Panen (bst) }\end{array}$}} \\
\hline & & & & & & & & & \\
\hline \multirow{2}{*}{$\begin{array}{l}\text { Bibit } \\
\text { tunas }\end{array}$} & Jarak tanaman & 5 & 7 & 9 & Rerata & 5 & 7 & 9 & Rerata \\
\hline & & \multicolumn{4}{|c|}{ Rimpang Basah Induk } & \multicolumn{4}{|c|}{ Rimpang Kering Induk } \\
\hline & JO & 203.33 & 306.67 & 256.67 & 255.55 & 32.80 & 41.40 & 28.87 & 34.36 \\
\hline \multirow[t]{3}{*}{$\mathrm{T} 1$} & J1 & 171.33 & 226.67 & 198.67 & 198.89 & 31.20 & 42.73 & 18.00 & 30.64 \\
\hline & $J 2$ & 240.00 & 306.67 & 295.33 & 280.67 & 32.47 & 38.60 & 22.27 & 31.11 \\
\hline & JO & 268.00 & 346.67 & 251.33 & 288.67 & 41.20 & 40.93 & 23.67 & 35.27 \\
\hline \multirow[t]{5}{*}{$\mathrm{T} 2$} & $\mathrm{~J} 1$ & 160.00 & 266.67 & 280.00 & 235.56 & 29.27 & 46.40 & 20.60 & 32.09 \\
\hline & $\mathrm{J} 2$ & 208.33 & 300.00 & 346.67 & 285.00 & 29.87 & 48.13 & 28.67 & 35.55 \\
\hline & Rerata & $208.50 \mathrm{~b}$ & $292.22 a$ & 271.44a & & $32.80 \mathrm{~b}$ & 43.03a & $23.68 c$ & \\
\hline & & \multicolumn{4}{|c|}{ Rimpang Basah Anak } & \multicolumn{4}{|c|}{ Rimpang Kering Anak } \\
\hline & JO & 233.33 & 266.67 & 296.67 & 265.56 & 27.00 & 29.67 & 19.80 & 25.49 \\
\hline \multirow[t]{3}{*}{$\mathrm{T} 1$} & $\mathrm{~J} 1$ & 268.00 & 213.33 & 179.67 & 220.33 & 32.60 & 26.53 & 15.27 & 24.80 \\
\hline & $\mathrm{J} 2$ & 273.33 & 340.00 & 237.67 & 283.67 & 24.33 & 33.67 & 13.73 & 23.91 \\
\hline & J0 & 258.00 & 340.00 & 304.00 & 300.67 & 29.00 & 36.00 & 23.47 & 29.49 \\
\hline \multirow[t]{3}{*}{$\mathrm{T} 2$} & $\mathrm{~J} 1$ & 210.00 & 200.00 & 303.33 & 237.78 & 29.67 & 23.20 & 13.13 & 22.00 \\
\hline & $\mathrm{J} 2$ & 239.00 & 240.00 & 240.00 & 239.67 & 37.73 & 32.27 & 14.00 & 28.00 \\
\hline & Rerata & 246.94 & 266.67 & 260.22 & & $30.06 a$ & $30.22 a$ & $16.57 \mathrm{~b}$ & \\
\hline & & \multicolumn{4}{|c|}{ Rimpang Basah Cucu } & \multicolumn{4}{|c|}{ Rimpang Kering Cucu } \\
\hline & JO & 340.00 & 180.00 & 156.67 & 225.56 & 15.47 & 10.20 & 6.13 & 10.60 \\
\hline \multirow[t]{3}{*}{$\mathrm{T} 1$} & $\mathrm{~J} 1$ & 247.67 & 120.00 & 105.67 & 157.78 & 22.33 & 9.20 & 4.53 & 12.02 \\
\hline & $\mathrm{J} 2$ & 255.33 & 200.00 & 119.33 & 191.56 & 16.80 & 12.47 & 3.67 & 10.98 \\
\hline & J0 & 320.00 & 140.00 & 170.00 & 210.00 & 16.47 & 13.67 & 7.00 & 12.38 \\
\hline \multirow[t]{3}{*}{$\mathrm{T} 2$} & J1 & 233.33 & 146.67 & 183.33 & 187.78 & 12.60 & 9.40 & 6.67 & 9.56 \\
\hline & $J 2$ & 276.67 & 180.00 & 183.33 & 213.33 & 16.00 & 14.13 & 5.20 & 11.78 \\
\hline & Rerata & 278.83a & 161.11b & $153.06 b$ & & $16.61 a$ & $11.51 \mathrm{~b}$ & $5.53 \mathrm{c}$ & \\
\hline
\end{tabular}

Keterangan: Berdasarkan uji Least Significant Difference (LSD), tidak ada perbedaan nyata ( $\alpha>0.05)$ pada angka-angka pada baris yang sama yang diikuti huruf yang sama dan yang tidak diikuti oleh huruf.. $J 0=$ temulawak $50 \mathrm{~cm} x$ $50 \mathrm{~cm}$ tanpa jagung; $J 1=$ temulawak $75 \mathrm{~cm} \times 60 \mathrm{~cm}$ dan jagung $100 \mathrm{~cm} \times 60 \mathrm{~cm}$; dan $\mathrm{J} 2=$ temulawak $75 \mathrm{~cm} \times$ $50 \mathrm{~cm}$ dan jagung $100 \mathrm{~cm} \times 60 \mathrm{~cm}$. T1 = 1-2 tunas); dan T2 = $\geq 3$ tunas

Data pada Tabel 1 menunjukkan bahwa waktu panen temulawak pada 5, 7, 9 bulan setelah penanaman mempengaruhi produktivitas rimpang, kecuali pada rimpang basah anak yang tidak berbeda nyata pada $\alpha=0.05$. Sementara itu jarak tanam dan jumlah tunas bibit relatif tidak menunjukkan pengaruh yang signifikan terhadap produktivitas rimpang tanaman temulawak. Berdasarkan usia panen, berat basah rimpang tertinggi dicapai pada usia tanam 7

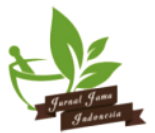


bulan kecuali untuk rimpang induk, berat basah tertinggi dicapai pada usia tanam 5 bulan.

Pada usia tanam temulawak 0-7 bulan merupakan fase vegetatif dimana proses fotosintesis masih berlangsung secara optimal sehingga tercermin pada tingkat pertumbuhan dan perkembangan tanaman temulawak berupa rimpang. Jarak tanam dan jumlah tunas tidak menunjukkan perbedaan yang signifikan terhadap berat rimpang sehingga dapat disimpulkan bahwa adanya tanaman tumpang sari tidak mempengaruhi proses metabolisme primer pada tanaman utama.

Secara alami temulawak tumbuh dengan baik di lahan-lahan yang teduh dan terlindung dari sinar matahari. Pemilihan pola penanaman tumpang sari dengan jarak tertentu dapat mempengaruhi produktivitas rimpang, dan juga sifat tanah. Hasil analisa agronomi temulawak dengan metode tumpang sari menunjukkan bahwa metode tumpangsari yang dilakukan sesuai dengan metode Rahardjo (2010) telah tepat, guna meningkatkan produktivitas lahan tanpa mempengaruhi produktivitas temulawak sebagai tanaman utama.

Penentuan tingkat produktivitas tanaman tidak terbatas pada hasil metabolisme primer dimana pada tanaman temulawak ditentukan dari ukuran dan bobot rimpang, tetapi juga didasarkan pada kadar senyawa metabolit sekunder yang dihasikan. Kadar senyawa metabolit sekunder menjadi faktor penting karena aplikasi tanaman herbal sebagai obat tradisional menitikberatkan pada efektivitas metabolit sekunder tersebut. Pada tanaman temulawak senyawa metabolit sekunder yang berperan penting adalah kurkuminoid dan xanthorrhizol (Sidik dan Sumiwi 2008).

Kurkuminoid merupakan salah satu senyawa utama dalam tanaman temulawak yang telah terbukti berkhasiat secara farmakologi (Nurcholis et al. 2016). Perbandingan kadar kurkuminoid pada waktu panen 5, 7, dan 9 bulan setelah tanam (bst) tersaji pada Gambar 2.

Kadar kurkuminoid tertinggi diperoleh pada usia tanaman 9 bst. Hal tersebut karena setelah tanaman temulawak selesai dengan proses metabolisme primer pada fase vegetatif (pertumbuhan tunas dan rimpang) maka proses beralih ke produksi metabolit sekunder, dan kadar metabolit sekunder mencapai optimum pada bulan ke-9 setelah penanaman.

Pengaruh jarak tanaman, tunas bibit, dan umur panen tanaman temulawak yang ditanam dengan atau tanpa tumpang sari dengan jagung terhadap kadar senyawa kurkuminoid temulawak tersaji pada Tabel 2. Kadar kurkuminoid tertinggi diperoleh dari kelompok jarak tanam temulawak $50 \mathrm{~cm} \times 50 \mathrm{~cm}$ tanpa adanya tumpang sari jagung pada umur panen 9 bst dan bibit dengan jumlah tunas $1-2$, yaitu sebesar $3.02 \%$. Pola yang serupa juga teramati dari hasil pengukuran rimpang anak dan rimpang cucu pada kelompok jarak tanam temulawak $50 \mathrm{~cm} \times 50 \mathrm{~cm}$ tanpa adanya

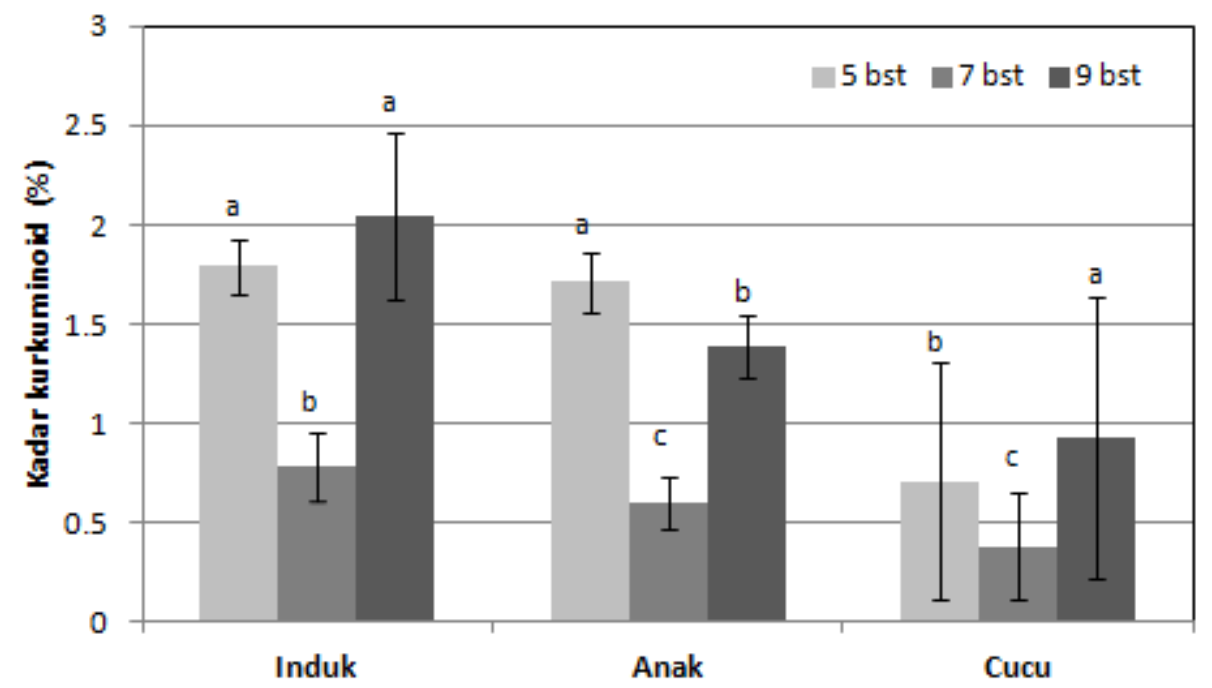

Gambar 2 Rerata kadar kurkuminoid dari berbagai kelompok perlakuan dilihat dari variabel usia panen. Berbeda huruf, siginifikan pada $\alpha=5 \%$ berdasarkan uji Least Significant Difference (LSD) pada rimpang sama. 
Tabel 2 Pengaruh jarak tanaman, tunas bibit, dan umur panen tanaman temulawak tumpang sari jagung terhadap kadar senyawa kurkuminoid temulawak

\begin{tabular}{|c|c|c|c|c|c|c|c|c|c|}
\hline \multirow{2}{*}{\multicolumn{2}{|c|}{ Perlakuan }} & \multicolumn{4}{|c|}{ Kadar Kurkuminoid (\%) } & \multicolumn{4}{|c|}{ Kadar Kurkuminoid (\%) } \\
\hline & & \multicolumn{4}{|c|}{ Umur Tanaman Panen (bst) } & \multicolumn{4}{|c|}{ Umur Tanaman Panen (bst) } \\
\hline \multirow{2}{*}{$\begin{array}{c}\text { Bibit } \\
\text { tunas }\end{array}$} & \multirow{2}{*}{ Jarak tanaman } & 5 & 7 & 9 & Rerata & 5 & 7 & 9 & Rerata \\
\hline & & \multicolumn{4}{|c|}{ Rimpang Induk } & \multicolumn{4}{|c|}{ Rimpang Anak } \\
\hline & J0 & $1.81 \mathrm{a}$ & $0.78 a$ & $3.02 a$ & 1.87 & $1.69 a$ & $0.48 a$ & $2.10 a$ & 1.42 \\
\hline \multirow[t]{3}{*}{$\mathrm{T} 1$} & J1 & $1.93 a$ & $0.91 a$ & $1.95 b$ & 1.60 & $1.83 a$ & $0.67 a$ & $1.21 \mathrm{~b}$ & 1.24 \\
\hline & $\mathrm{J} 2$ & $1.75 a$ & $0.76 a$ & $1.69 b$ & 1.40 & $1.86 a$ & $0.69 a$ & $1.14 \mathrm{~b}$ & 1.23 \\
\hline & J0 & $1.79 a$ & $0.69 a$ & $1.60 a$ & 1.36 & $1.60 a$ & $0.62 \mathrm{a}$ & $1.05 a$ & 1.09 \\
\hline \multirow[t]{3}{*}{$\mathrm{T} 2$} & J1 & $1.82 \mathrm{a}$ & $0.71 a$ & $1.83 a$ & 1.45 & $1.69 a$ & $0.55 a$ & $1.24 a$ & 1.16 \\
\hline & $J 2$ & $1.65 a$ & $0.84 a$ & $2.14 a$ & 1.54 & $1.58 \mathrm{a}$ & $0.60 a$ & $1.58 \mathrm{a}$ & 1.25 \\
\hline & Rerata & $1.79 a$ & $0.78 b$ & $2.04 a$ & & $1.71 a$ & $0.60 c$ & $1.39 \mathrm{~b}$ & \\
\hline \multicolumn{10}{|c|}{ Rimpang Cucu } \\
\hline \multirow{4}{*}{$\mathrm{T} 1$} & J0 & 0.68 & 0.48 & 1.28 & 0.82 & & & & \\
\hline & J1 & 0.82 & 0.27 & 0.82 & 0.64 & & & & \\
\hline & $\mathrm{J} 2$ & 0.69 & 0.38 & 0.71 & 0.60 & & & & \\
\hline & JO & 0.74 & 0.38 & 0.65 & 0.59 & & & & \\
\hline \multirow[t]{3}{*}{$\mathrm{T} 2$} & J1 & 0.73 & 0.45 & 0.91 & 0.70 & & & & \\
\hline & $\mathrm{J} 2$ & 0.61 & 0.31 & 1.18 & 0.70 & & & & \\
\hline & Rerata & $0.71 b$ & $0.38 c$ & $0.93 a$ & & & & & \\
\hline
\end{tabular}

Keterangan: Berdasarkan uji Least Significant Difference (LSD), tidak ada perbedaan nyata $(\alpha>0.05)$ pada angka-angka pada baris yang sama yang diikuti huruf yang sama dan yang tidak diikuti oleh huruf. $J 0=$ temulawak $50 \mathrm{~cm}$ $\times 50 \mathrm{~cm}$ tanpa jagung; $J 1=$ temulawak $75 \mathrm{~cm} \times 60 \mathrm{~cm}$ dan jagung $100 \mathrm{~cm} \times 60 \mathrm{~cm}$; dan $\mathrm{J} 2=$ temulawak $75 \mathrm{~cm}$ $x 50 \mathrm{~cm}$ dan jagung $100 \mathrm{~cm} \times 60 \mathrm{~cm}$. T1 = 1-2 tunas); dan $\mathrm{T} 2=\geq 3$ tunas

tumpang sari jagung pada umur panen 9 bst dan bibit dengan jumlah tunas 1-2, yang secara berutan memberikan kadar kurkuminoid sebesar $2.10 \%$ dan 1.28\%. Kadar kurkuminoid terbanyak kedua diperoleh dari kelompok jarak tanam temulawak $75 \mathrm{~cm} \times 50 \mathrm{~cm}$ dengan tumpang sari jagung dan jumlah tunas $\geq 3$ yang memberikan kadar kurkuminoid sebesar $2.18 \%$ untuk rimpang induk, $1.58 \%$ untuk rimpang anak, dan $1.18 \%$ untuk rimpang cucu. Hasil tersebut menunjukan bahwa tidak ada perbedaan yang signifikan $(\alpha>0.05)$ pada kadar kurkuminoid dari kelompok perlakukan jarak tanam yang berbeda dan juga antara penanaman dengan ataupun tanpa tumpang sari.

Secara umum kadar xanthorrhizol tertinggi diperoleh dari temulawak pada umur 9 bst, yang diikuti dengan temulawak pada umur 5 dan 7 bst (Gambar 3). Kadar xanthorrhizol pada rimpang induk yang mencapai $4.81 \%$ pada umur 9 bst, menunjukan perbedaan yang signifikan dengan kadar xanthorrhizol dari temulawak pada umur 5 bst (2.93\%) dan 7 bst (2.20\%). Pola yang serupa juga teramati pada rimpang anak dengan kadar xanthorrhizol tertinggi sebesar 4.00\% diperoleh dari temulawak pada umur 9 bst diikuti pada umur 5 bst (3.17\%) dan 7 bst (2.08\%) (perbedaan signifikan pada $\alpha=0.05$ ). Sementara itu pada rimpang cucu juga menunjukkan pola yang sama, yaitu kadar xanthorrhizol tertinggi pada 9 bst (3.95\%) diikuti 5 bst (2.03\%) dan 7 bst (1.75\%).

Hasil pengukuran kadar xanthorrhizol pada berbagai variasi perlakuan (Tabel 3) menunjukkan bahwa kadar xanthorrhizol pada rimpang induk dan anak hanya dipengaruhi waktu panen tetapi tidak dipengaruhi oleh perlakuan jarak tanam, tumpang sari jagung, dan jumlah tunas bibit yang digunakan, namun pada rimpang cucu kadar xanthorrhizol dipengaruhi oleh jarak tanam dan waktu panen.

Kadar xanthorrhizol tertinggi yakni sebesar 5.71\% diperoleh dari temulawak dengan pola tanam $75 \mathrm{~cm} \mathrm{x}$ $60 \mathrm{~cm}$ jarak tanam temulawak dan jagung $100 \mathrm{~cm} \times 60$ $\mathrm{cm}$, tunas bibit $>3$ dan dipanen pada usia 9 bst. Namun berdasarkan uji Least Significant Difference (LSD), hasil tersebut tidak menunjukan perbedaan yang signifikan $(\alpha>0.05)$ dengan kadar xanthorrhizol dari kelompok perlakuan lainnya.

Hasil pengukuran kadar kurkuminoid dan xanthorrhizol menunjukkan bahwa meskipun dengan diterapkannya metode budi daya tumpang sari yang diduga akan meningkatkan kemungkinan terjadinya 


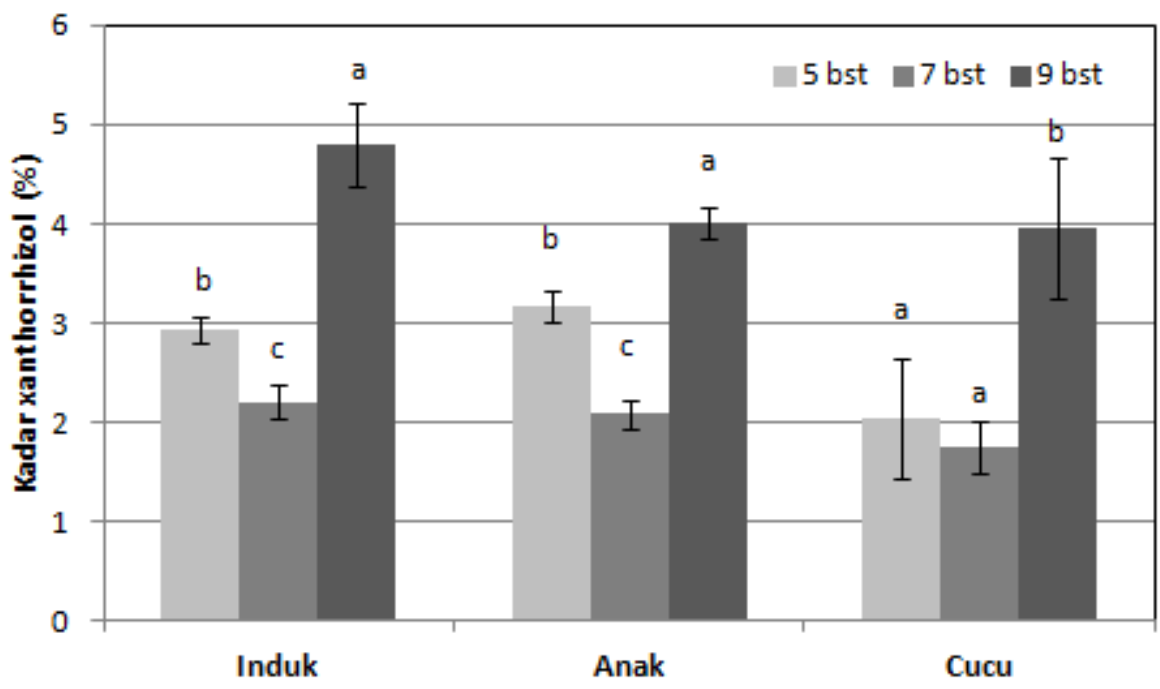

Gambar 3 Rerata kadar xanthorrhizol dari berbagai kelompok perlakuan dilihat dari variabel usia panen. Berbeda huruf siginifikan pada $\alpha=5 \%$ berdasarkan uji Least Significant Difference (LSD) pada rimpang sama.

Tabel 3 Pengaruh jarak tanaman, tunas bibit, dan umur panen tanaman temulawak tumpang sari jagung terhadap kadar senyawa xanthorrhizol

\begin{tabular}{|c|c|c|c|c|c|c|c|c|c|}
\hline \multirow{2}{*}{\multicolumn{2}{|c|}{ Perlakuan }} & \multicolumn{4}{|c|}{ Kadar Xanthorrhizol (\%) } & \multicolumn{4}{|c|}{ Kadar Xanthorrhizol (\%) } \\
\hline & & \multicolumn{4}{|c|}{ Umur Tanaman Panen (bst) } & \multicolumn{4}{|c|}{ Umur Tanaman Panen (bst) } \\
\hline \multirow{2}{*}{$\begin{array}{l}\text { Bibit } \\
\text { tunas }\end{array}$} & \multirow{2}{*}{ Jarak tanaman } & 5 & 7 & 9 & Rerata & 5 & 7 & 9 & Rerata \\
\hline & & \multicolumn{4}{|c|}{ Rimpang Induk } & \multicolumn{4}{|c|}{ Rimpang Anak } \\
\hline & $\mathrm{JO}$ & 2.88 & 2.27 & 4.07 & 3.07 & 3.17 & 2.12 & 3.70 & 3.00 \\
\hline \multirow[t]{3}{*}{$\mathrm{T} 1$} & $\mathrm{~J} 1$ & 2.86 & 2.41 & 5.11 & 3.46 & 3.15 & 2.06 & 3.70 & 2.97 \\
\hline & $\mathrm{J} 2$ & 2.99 & 1.96 & 4.72 & 3.22 & 3.42 & 1.95 & 4.24 & 3.20 \\
\hline & J0 & 2.88 & 2.15 & 4.25 & 3.09 & 3.02 & 2.30 & 3.96 & 3.09 \\
\hline \multirow[t]{3}{*}{$\mathrm{T} 2$} & J1 & 3.18 & 2.15 & 5.71 & 3.68 & 3.28 & 2.09 & 4.36 & 3.24 \\
\hline & $\mathrm{J} 2$ & 2.78 & 2.27 & 5.01 & 3.35 & 2.95 & 1.94 & 4.04 & 2.98 \\
\hline & Rerata & $2.93 b$ & $2.20 c$ & 4.81a & & $3.17 b$ & $2.08 \mathrm{c}$ & $4.00 a$ & \\
\hline \multicolumn{10}{|c|}{ Rimpang Cucu } \\
\hline & J0 & 1.92 & 1.82 & 3.18 & 2.31 & & & & \\
\hline \multirow[t]{3}{*}{$\mathrm{T} 1$} & J1 & 1.93 & 1.65 & 3.57 & 2.38 & & & & \\
\hline & $\mathrm{J} 2$ & 1.61 & 1.97 & 3.93 & 2.50 & & & & \\
\hline & JO & 2.17 & 1.82 & 3.43 & 2.47 & & & & \\
\hline \multirow[t]{3}{*}{$\mathrm{T} 2$} & J1 & 2.80 & 1.74 & 4.75 & 3.10 & & & & \\
\hline & $J 2$ & 1.77 & 1.52 & 4.87 & 2.72 & & & & \\
\hline & Rerata & $2.03 a$ & $1.75 a$ & $3.95 b$ & & & & & \\
\hline
\end{tabular}

Keterangan: Berdasarkan uji Least Significant Difference (LSD), tidak ada perbedaan nyata $(\alpha>0.05)$ pada angka-angka pada baris yang sama yang diikuti huruf yang sama dan yang tidak diikuti oleh huruf. $J 0=$ temulawak $50 \mathrm{~cm}$ x $50 \mathrm{~cm}$ tanpa jagung; $J 1=$ temulawak $75 \mathrm{~cm} \times 60 \mathrm{~cm}$ dan jagung $100 \mathrm{~cm} \times 60 \mathrm{~cm}$; dan $\mathrm{J} 2=$ temulawak 75 $\mathrm{cm} \times 50 \mathrm{~cm}$ dan jagung $100 \mathrm{~cm} \times 60 \mathrm{~cm}$. T1 = 1-2 tunas); dan $\mathrm{T} 2=\geq 3$ tunas

kompetisi antar tanaman untuk memperoleh unsur hara tanah ternyata tidak memberikan pengaruh yang signifikan terhadap pembentukan metabolit sekunder dari temulawak. Sebaliknya, terdapat keuntungan yang dapat timbul dengan diterapkannya metode tumpang sari ini, yaitu meningkatnya potensi perbaikan kondisi tanah melalui penyeimbangan kembali kondisi mikrobiota dan sifat kimia tanah di lapisan rhizosfer. Keseimbangan mikrobiota dan perbaikan sifat kimia tanah yang terjadi ditandai dengan peningkatan 
kandungan nitrogen, fosfor, serta penurunan $\mathrm{pH}$ tanah (Song et al. 2006). Nitrogen, fosfor, serta pH tanah merupakan faktor penunjang dalam pertumbuhan dan kadar senyawa aktif pada tanaman. Adanya perbaikan kondisi tanah menyebabkan metabolisme primer dan sekunder dari tanaman akan berjalan lebih optimal. Nitrogen dan fosfor merupakan unsur hara primer yang dibutuhkan secara makro. Nitrogen menyusun 1-5\% dari berat tanaman dan berfungsi menyusun asam amino, asam nukleat, nukleotida, dan klorofil sehingga dapat mempercepat pertumbuhan tanaman, dan juga berperan dalam pembentukan hasil metabolisme primer dan sekunder dari tanaman. Sedangkan elemen fosfor dapat memacu pertumbuhan akar dan membentuk sistem perakaran yang baik, menyusun dan menstabilkan dinding sel sehingga menambah daya tahan tanaman terhadap serangan hama penyakit (Razaq et al. 2017).

Penerapan metode penanaman tumpang sari temulawak dengan jagung terbukti tidak mempengaruhi produktivitas tanaman temulawak baik secara berat basah, berat kering ataupun kandungan kukurminoid dan xanthorrhizol. Disamping itu, penerapan metode tumpang sari ini diharapkan dapat pula memperbaiki kondisi dan kualitas tanah, sehingga dapat mengefisiensikan proses pengolahan tanah untuk penanaman temulawak selanjutnya. Efisiensi proses pengolahan tanah ini dapat diawali dengan meminimalisasi periode pengolahan tanah dan pemupukan, namun diharapkan dapat tetap menghasilkan temulawak dengan kualitas yang sama dengan sebelumnya. Oleh karena itu, penelitian lebih mendalam terkait hal ini perlu untuk dilakukan lebih lanjut.

\section{KESIMPULAN}

Produktivitas rimpang yang merupakan hasil dari proses metabolisme primer temulawak dipengaruhi oleh waktu panen, dengan hasil tertinggi tercapai pada waktu 7 bulan setelah tanam. Hasil pengukuran kadar kurkuminoid dan xanthorrhizol pun menunjukkan bahwa kandungaan metabolit sekunder temulawak ini dipengaruhi oleh waktu panen, dengan hasil tertinggi tercapai pada saat tanaman berumur 9 bulan setelah tanam. Perbedaan perlakuan pada proses penanaman menunjukan hampir tidak ada perbedaan yang signifikan $(\alpha>0.05)$ pada kadar metabolit sekunder temulawak dari kelompok perlakukan jarak tanam yang berbeda dan juga antara penanaman dengan ataupun tanpa tumpang sari.

Hal ini membuktikan bahwa metode tanam tumpang sari tidak mempengaruhi produktivitas rimpang dan kadar bahan aktif yang terkandung di dalamnya, sehingga dapat menjadi pilihan metode pertanian untuk meningkatkan manfaat ekonomi para petani temulawak.

\section{DAFTAR PUSTAKA}

Arafa H. 2005. Curcumin attenuates diet-induced hypercholesterolemia in rats. Medical Science Monitor. 11(7):228-234.

Devy L. 2009. Analysis of variance and genetic stability of temulawak (Curcuma xanthorrhiza Roxb.) in Indonesia. [tesis]. Bogor (ID): Sekolah Pascasarjana, Institut Pertanian Bogor.

Farombi E, Shrotriya S, Na H, Kim D, Surh Y. 2007. Curcumin attenuates dimethylnitrosamineinduced liver injury in rats through Nrf2mediated induction of heme oxygenase-1. Food and Chemical Toxicology. 46(4):1279-1287.

Figueiredo AC, Barroso JG, Pedro LG, Scheffer JJ. 2008. Factors affecting secondary metabolite production in plants: volatile components and essential oils. Flavour and Fragrance Journal. 23:213-226.

Goel A, Kunnumakkara A, Aggarwal B. 2008. Curcumin as "Curecumin": from kitchen to clinic. Biochemical Pharmacology. 75(4):787-809.

Herlina. 2011. Kajian variasi jarak dan waktu tanam jagung manis dalam sistem tumpang sari jagung manis (Zea mays). Padang (ID): Universitas Andalas.

Indriati TR. 2009. Pengaruh Dosis Pupuk Organik dan Populasi Tanaman terhadap Pertumbuhan serta Hasil Tumpang sari Kedelai (Glycine max L.) dan Jagung (Zea mays L.). [tesis]. Surakarta (ID): Program Pascasarjana, Universitas Sebelas Maret.

Islam F, Karim MR, Shahjahan M, Hoque MO, Alam MR, Hossain MA. 2002. Study on the effect of plant spacing on the production of turmeric at farmer's field. Asian Journal of Plant Sciences. 1(6):616617.

Jacob A, Wu R, Zhou M, Wang P. 2007. Mechanism of the Anti-inflammatory Effect of Curcumin: PPARgamma Activation. PPAR Research. 2007, 89369.

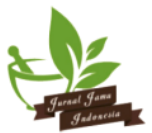


Kumar P, Padi S, Naidu P, Kumar A. 2007. Possible neuroprotective mechanisms of curcumin in attenuating 3-nitropropionic acid-induced neurotoxicity. Methods and Findings in Experimental and Clinical Pharmacology. 29(1):19-25.

Nurcholis W, Ambarsari L, Purwakusumah ED. 2016. Curcumin analysis and cytotoxic activities of some Curcuma xanthorrhiza Roxb. Accessions. International Journal of Pharm Tech Research. 9(7):175-180.

Rahardjo M. 2010. Penerapan SOP budi daya untuk mendukung temulawak sebagai bahan baku obat potensial. Perspektif. 9(2):78-93.

Razaq M, Zhang P, Shen H, Salahuddin. 2017. Influence of nitrogen and phosporus on the growth and root morphology of Acer Mono. PLOS ONE. 12(2):e0171321
Sidik, Sumiwi SA. 2009. Temulawak (Curcuma xanthorrhiza Roxb.) Botany, Etnobotany Chemistry, Pharmacology and There Benefit. Proceedings of The First International Symposium on Temulawak. 27-28 May 2008. Bogor (ID): Biopharmaca Research Center Bogor Agricultural University .

Song YN, Zhang FS, Marschner P, Fan FL, Gao HM, Bao $X G$, Li L. 2007. Effect of intercropping on crop yield and chemical and microbiological properties in rizhosfer of wheat (Triticum aestivum L.), maize (Zea mays L.), and faba bean (Vicia faba L.). Biology and Fertility of Soils. 43(5):565-574.

Thangapazham R, Puri A, Tele S, Blumenthal R, Maheshwari R. 2008. Evaluation of a nanotechnology-based carrier for delivery of curcumin in prostate cancer cells. International Journal of Oncology. 32(5):1119-1123. 